\title{
Vedolizumab in Inflammatory Bowel Disease: West versus East
}

\author{
Prasanta Debnath Pravin M. Rathi \\ T.N.M.C. \& B.Y.L. Nair Charitable Hospital, Mumbai, India
}

\section{Keywords}

Vedolizumab - Ulcerative colitis · Crohn's disease

\begin{abstract}
Background: Vedolizumab is a humanized immunoglobulin G1 monoclonal antibody, which binds to a $4 \beta 7$ integrin on $T$ lymphocytes, thus disturbing the interaction with mucosal vascular addressin cell adhesion molecule 1 on the intestinal endothelial cells to interfere with lymphocyte trafficking to the gut. Summary: Vedolizumab is a safe and effective drug to induce and maintain clinical remission in patients with Crohn's disease (CD) and ulcerative colitis (UC) in both clinical trials and real-world data. Various guidelines recommend vedolizumab as a first- or second-line treatment regimen for steroid-dependent, steroid, or immunomodulator refractory cases of UC and CD; however, it is more effective in anti-TNFnaive patients. The first head-to-head trial (VARSITY trial) comparing the efficacy of vedolizumab to adalimumab has shown better clinical remission and mucosal healing with vedolizumab. Key Messages: In this review, we have discussed guidelines recommendation of vedolizumab use, as well as its safety data, use in special population, in presence of extraintestinal complications, therapeutic drug monitoring, data from Asian patients, along with other evolving concepts. Because of its excellent safety data and low immuno-
\end{abstract}

karger@karger.com www.karger.com/iid

Karger"

GOPEN ACCESS
(C) 2021 The Author(s)

Published by S. Karger AG, Basel

This is an Open Access article licensed under the Creative Commons Attribution-NonCommercial-4.0 International License (CC BY-NC) (http://www.karger.com/Services/OpenAccessLicense), applicable to the online version of the article only. Usage and distribution for commercial purposes requires written permission. genicity, vedolizumab is an impressive option for patients with prior malignancy and less chance of reactivation of tuberculosis; however, cost remains an issue.

(C) 2021 The Author(s)

Published by S. Karger AG, Basel

\section{Introduction}

Inflammatory bowel disease (IBD) is a chronic idiopathic inflammatory condition of relapsing-remitting type of the gastrointestinal tract, often associated with high morbidity due to both disease and treatment-related complications. Conventional management of IBD includes broad-spectrum anti-inflammatory drugs such as aminosalicylates and corticosteroids and immunosuppressants such as thiopurines or methotrexate, often used in a step-up manner, aiming to relieve symptoms and to an extent prevent long-term complications [1]. Around $30 \%$ of ulcerative colitis (UC) and 50\% of Crohn's disease (CD) patients may require surgery in their lifetime [2]. Anti-tumor necrosis factor (TNF) therapies, added to the treatment armamentarium since 1997, changed natural history of IBD by decreasing the risk of surgery and hospitalization, especially when used early in the treatment course [3]. IBD management had a paradigm shift, espe- 
cially in the setting of fistulizing CD and acute severe colitis [4]. However, up to one-third of patients do not respond to anti-TNF agents and about $40 \%$ stop responding in future due to subtherapeutic drug levels, development of antidrug antibodies (ADAs), or because of mechanistic escape where another cytokine may become more important in disease pathogenesis $[4,5]$. Few patients may require a change in drug class, due to side effects like drug-induced lupus, psoriasis, drug-induced liver injury, or demyelinating disease [6].

\section{Vedolizumab: Mechanism of Action}

Circulating leukocytes activate a highly coordinated sequential adhesion pathway, which involves tethering, rolling, activation, adhesion, and migration through the vascular wall. Various pro-inflammatory cytokines are released by infiltrating leukocytes, which activate endothelial cell, leading to upregulation of adhesion molecules of integrin family and enhancement of inflammatory cell recruitment. Integrins (leukocyte cell surface adhesion molecules) allow them to stop rolling and start migration through the vascular wall [7]. Integrins involved in T-cell migration are leukocyte function-associated antigen 1 (LFA-1 or $\alpha 2 \beta 2)$ and the two $\alpha 4$-integrins ( $\alpha 4 \beta 1$ and $\alpha 4 \beta 7$ ), which bind to specific endothelial ligands called addressins, namely, vascular cell adhesion molecule-1 (VCAM-1), mucosal vascular addressin cell adhesion molecule-1 (MAdCAM-1), and intercellular adhesion molecule-1 (ICAM-1) [7, 8]. The integrin $\alpha 4 \beta 7$ is expressed on lymphocytes in gut-associated lymphoid tissue, which interacts with MAdCAM-1 and activates gutspecific migration of lymphocytes to Peyer's patches. Integrins $\alpha 4 \beta 1$ and $\alpha 2 \beta 2$ interact with VCAM-1 and ICAM-1, respectively. The biologic agents involved are natalizumab (anti- $\alpha 4$ integrin), vedolizumab (anti- $\alpha 4 \beta 7$ integrin), and etrolizumab (anti- $\beta 7$ integrin targeting both $\alpha 4 \beta 7$ and $\alpha E \beta 7$ integrins) [8].

Vedolizumab, a humanized monoclonal antibody targeting a $4 \beta 7$ integrin, has proven to be a safe and efficacious drug to induce and maintain clinical remission in patients with IBD and has received regulatory approval (the U.S. Food and Drug Administration and the European Medicines Agency) for the treatment of patients with moderate-to-severe UC and CD in 2014. It does not involve $\alpha 4 \beta 1$-VCAM interactions or T-cell trafficking to the brain or kidney. As such, it is not directly linked with risk of progressive multifocal leukoencephalopathy, which is a rare viral disease associated with high mortality $[9,10]$. Although it has always been considered to interfere mainly with lymphocyte trafficking to the gut, a detailed characterization of its immunological mode of action recently pointed primarily toward its influence on the innate rather than on the adaptive immune system [11].

In this review, we will discuss the role of new kid on the block in Indian market, vedolizumab, in the management of IBD patients and compare data available from Asian countries. We will review the guideline recommendations from various societies for use of vedolizumab in both UC and CD, followed by data from registrational trials including open-label extension, observational study, and emerging real-world evidence to suggest its efficacy and safety. The potential implications, indication, and side effect profile along with cost-effectiveness will also be discussed.

\section{Methods}

A thorough literature search was conducted using different databases (PubMed, Embase, Google Scholar, and Scopus) to identify all relevant articles published until March 2020. The selection of references was based on appropriateness of study design, number of patients, and publication in peer-reviewed journals with prioritization of original articles.

\section{Vedolizumab in UC}

The guideline recommendations regarding the use of vedolizumab in patients with UC are presented in Table 1 .

\section{Clinical Trial Data of Vedolizumab in UC}

GEMINI I Study

Feagan et al. [17] conducted 2 integrated randomized, double-blind, placebo-controlled trials of vedolizumab in patients with active UC.

\section{Induction Therapy Trial}

Cohort 1:374 patients received vedolizumab (at a dose of $300 \mathrm{mg}$ ) or placebo at weeks 0 and 2 .

Cohort 2: 521 patients received open-label vedolizumab at weeks 0 and 2, with disease evaluation at week 6 .

The primary endpoint was clinical response at week 6 , defined by a reduction in the Mayo score of $\geq 3$ points and a decrease of at least $30 \%$ from baseline, with a decrease of the rectal bleeding subscore of $\geq 1$ point (absolute score $0-1) .47 .1 \%$ achieved clinical response at week 6 in the vedolizumab group as compared with $25.5 \%$ in the placebo group $(p<0.001)$. 
Table 1. Vedolizumab in UC - guideline recommendations

Society Statement

ACG [12], $2019 \quad$ (A) Induction of remission in moderately to severely active UC:

(i) ACG recommends vedolizumab for induction of remission (strong recommendation, moderate quality of evidence)

(ii) ACG recommends vedolizumab for induction of remission in patients who have previously failed anti-TNF therapy (strong recommendation, moderate quality of evidence)

(B) Maintenance of remission in patients with previously moderately to severely active UC:

(i) ACG recommends continuing vedolizumab to maintain remission in patients who had remission after vedolizumab induction

(strong recommendation, moderate quality of evidence)

(ii) In patients with ASUC, who achieve remission with cyclosporine treatment, ACG suggests maintenance of remission with vedolizumab (conditional recommendation, very low quality of evidence)

ECCO [13], 2017 (A) Steroid-dependent active UC:

Patients should be treated with a thiopurine [EL2], anti-TNF [EL1], vedolizumab [EL2], or methotrexate [EL2] and in case of treatment failure, second-line medical therapy with an alternative anti-TNF [EL4], vedolizumab [EL2], or colectomy [EL5] should be considered

(B) Oral steroid-refractory active UC:

Steroid refractory moderate disease should be treated with intravenous steroids [EL4], anti-TNF [EL1], vedolizumab [EL2], or tacrolimus [EL2]

Second-line medical therapy with a different anti-TNF [EL4] or vedolizumab [EL2] may be an option

(C) Immunomodulator-refractory UC:

Moderate colitis refractory to thiopurines should be treated with anti-TNF [EL1] or vedolizumab [EL2]

In case of treatment failure, a different anti-TNF [EL4] or vedolizumab [EL2] should be considered, and colectomy if further medical therapy fails [EL5]

(D) Medications for maintenance of remission:

Anti-TNF or vedolizumab may be used as first-line biological therapy

Vedolizumab is effective in patients failing anti-TNF [EL2]

Maintenance therapy with vedolizumab is appropriate in patients responding to vedolizumab therapy [EL2]

(E) Duration of maintenance therapy:

No recommendation for the duration of treatment with vedolizumab exists, although prolonged use may be needed [EL4]

AGA [14], $2020 \quad$ (A) Adult outpatients with moderate-to-severe UC:

(i) AGA recommends using anti-TNF agents, vedolizumab, tofacitinib, or ustekinumab over no treatment (strong recommendation, moderate-quality evidence)

(ii) In patients who are naive to biologic agents, AGA suggests using infliximab or vedolizumab rather than adalimumab for induction of remission (conditional recommendation, moderate-quality evidence)

(iii) Patients who have previously been exposed to infliximab, particularly those with primary nonresponse, AGA suggests using ustekinumab or tofacitinib rather than vedolizumab or adalimumab for induction of remission (conditional recommendation, low-quality evidence)

(iv) AGA suggests using biologic monotherapy (TNF- $\alpha$ antagonists, vedolizumab, or ustekinumab) or tofacitinib rather than thiopurine monotherapy for induction of remission (conditional recommendation, low-quality evidence)

(v) AGA suggests combining anti-TNF agents, vedolizumab, or ustekinumab with thiopurines or methotrexate rather than biologic or thiopurine monotherapy (conditional recommendation, low-quality evidence)

(vi) AGA suggests early use of biologic agents with or without immunomodulator therapy rather than gradual step-up after failure of 5-ASA (conditional recommendation, very low-quality evidence)

(B) Adult outpatients with moderate-to-severe UC in remission:

AGA makes no recommendation in favor of, or against, using anti-TNF agents, vedolizumab, or ustekinumab, rather than thiopurine monotherapy for of remission (no recommendation, knowledge gap)

BSG [15], $2019 \quad$ (A) In corticosteroid-dependent or refractory UC:

BSG recommends treatment escalation with:

(i) Thiopurine (strong recommendation, moderate-quality evidence)

(ii) Anti-TNF therapy (strong recommendation, high-quality evidence)

(iii) Vedolizumab (strong recommendation, high-quality evidence)

(iv) Tofacitinib (strong recommendation, high-quality evidence)

(B) Induction and maintenance of remission in UC:

BSG recommends vedolizumab can be used in patients where anti-TNF treatment has failed (strong recommendation, high-quality evidence)

(C) Immunomodulator refractory UC:

BSG recommends anti-TNF therapy, ustekinumab, or vedolizumab (strong recommendation, very low-quality evidence)

APAGE [16], 2010 No recommendation regarding use of vedolizumab in UC

UC, ulcerative colitis; TNF, tumor necrosis factor. 
Table 2. Vedolizumab use in UC and CD trials

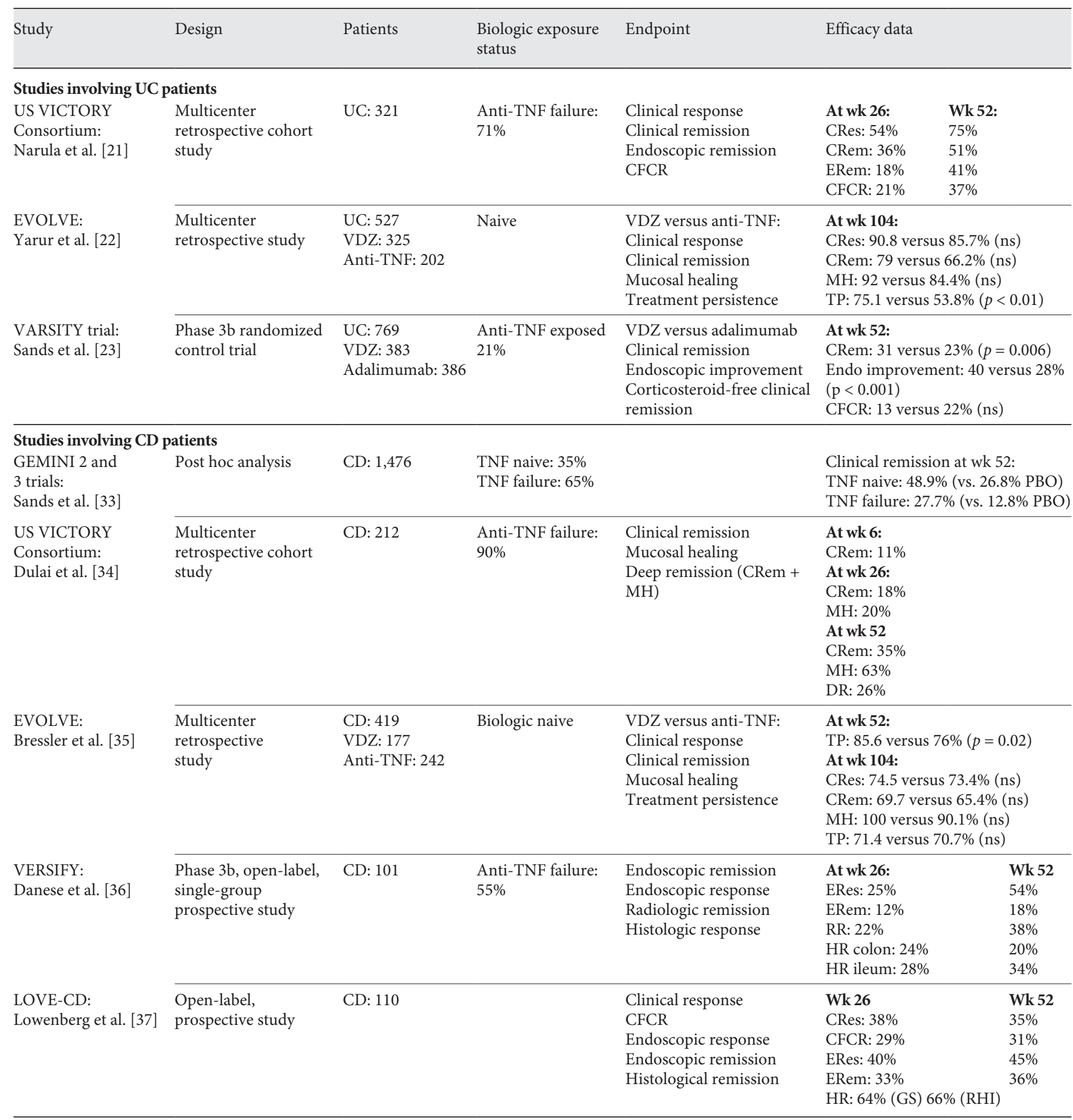

CD, Crohn's disease; CFCR, corticosteroid-free clinical remission; CRem, clinical remission; CRes, clinical response; DR, deep remission; ERem, endoscopic remission; ERes, endoscopic response; GS, Geboes score; HR, histological remission; LOVE-Cd, LOw Countries VEdolizumab in CD Study; MH, mucosal healing; ns, not significant; RHI, Robarts Histopathology Index; TNF, tumor necrosis factor; TP, treatment persistence; UC, ulcerative colitis; US VICTORY Consortium, US VICTORY (Vedolizumab for Health OuTComes in InflammatORY Bowel Diseases) Consortium; VDZ, vedolizumab. 
Maintenance Therapy Trial

Patients who had a response to vedolizumab at week 6 were randomly assigned to vedolizumab every 8 or 4 weeks or placebo for up to 52 weeks. The primary endpoint was clinical remission at week 52 , defined by a total Mayo score of $\leq 2$ and no subscore $>1$ on any of the 4 Mayo scale components, which was seen in $41.8 \%$ of patients treated with vedolizumab every 8 weeks, $44.8 \%$ treated with vedolizumab every 4 weeks, and $15.9 \%$ of patients receiving placebo ( $p<0.001$, both).

The GEMINI open-label extension study, which followed patients $(n=154)$ on long-duration vedolizumab, found that of patients responding to induction therapy and who completed the maintenance study, $40.9 \%$ of patients had 248 weeks of treatment [18]. Of them, $98 \%$ achieved clinical response and $90 \%$ had clinical remission. Significant improvements in patient-reported outcomes of reduction in rectal bleeding and stool frequency as early as 2 weeks were reported on post hoc analysis of the GEMINI trials [19]. Vedolizumab was found to be superior to placebo for clinical response, induction of remission, endoscopic remission and remission at 52 weeks in week 6 responders in a Cochrane systematic review [20].

\section{"Real-World" Experience in UC}

Data from real-world studies provide further credible evidence for effectiveness and safety of vedolizumab in UC, which is shown in Table 2. The US VICTORY Consortium reported clinical and endoscopic remission in 51 and $41 \%$ of patients, respectively, at 12 months [21]. Previous anti-TNF exposure was associated with lower rates of clinical (HR: 0.53, 95\% CI: 0.38-0.75) and endoscopic remission (HR: 0.51, 95\% CI: 0.29-0.88).

Yarur et al. [22] retrospectively assessed the safety and effectiveness of vedolizumab compared with anti-TNF agents in a real-world cohort of biologic-naive patients with UC. At 2 years, cumulative rates of clinical response, clinical remission, and mucosal healing did not differ significantly between the vedolizumab and anti-TNF groups. However, higher treatment persistence $(p<0.01)$ occurred in the vedolizumab group, and dose escalation was more common in the anti-TNF group $(p<0.05)$.

With an expanding therapeutic armamentarium, the inevitable question and challenge for clinicians and patients is choosing between treatment classes. The first head-to-head trial, which compared vedolizumab with adalimumab in a double-blind, double-dummy, randomized controlled trial, the VARSITY trial, has shown vedolizumab to be more effective than adalimumab in attaining clinical remission ( 31.3 vs. $22.5 \%, p=0.006)$ and endoscopic improvement ( 39.7 vs. $27.7 \%, p<0.001)$ at 52 weeks [23]. Corticosteroid-free clinical remission occurred in $12.6 \%$ of the patients in the vedolizumab group and in $21.8 \%$ in the adalimumab group. Exposure-adjusted incidence rates of infection and corresponding rates for serious infection were more in the adalimumab group than in the vedolizumab group. This study along with recent systematic reviews with network meta-analysis reported that vedolizumab and infliximab ranked highest for induction of clinical remission in biologic-naive UC patients and that vedolizumab was associated with the lowest risk of serious adverse events and infections [24, 25].

The pitfalls of the VARSITY trial, which one has to look for, are few: first the funding, which was done by the manufacturer of vedolizumab (Takeda); second, previous exposure to anti-TNF therapies was allowed (although restricted to $25 \%$ ); third, the lack of dose escalation in either treatment group, as dose escalation is more typically performed with adalimumab than with vedolizumab in clinical practice, which may have skewed the results in favor of vedolizumab [26]. Although most of the guidelines advise vedolizumab, ustekinumab, or tofacitinib in antiTNF-exposed cases, the AGA, in particular, suggests ustekinumab or tofacitinib over vedolizumab based on recent network meta-analysis by Singh et al. [27]. In the VARSITY trial, there was no significant difference in rates of achieving clinical remission at week 52 (20.3 vs. $16.0 \%)$, and the overall body of evidence was deemed to be of low quality. Network meta-analysis of 7 RCTs with 1,580 patients with prior exposure to anti-TNF agents showed low confidence in estimates supporting higher efficacy of tofacitinib and ustekinumab over vedolizumab (tofacitinib vs. vedolizumab: OR, 6.18; 95\% CI, 1.0038.00; ustekinumab vs. vedolizumab: OR, 5.99; $95 \% \mathrm{CI}$, 1.13-31.76) for induction of clinical remission in such patients [14].

\section{Vedolizumab in CD}

The guideline recommendations regarding the use of vedolizumab in patients with $\mathrm{CD}$ are presented in Table 3 .

\section{Clinical Trial Data of Vedolizumab in CD}

GEMINI 2 Trial

Sandborn et al. [31] in their integrated study with separate induction and maintenance trials included patients with moderately to severely active $\mathrm{CD}$. 
Table 3. Vedolizumab in CD - guideline recommendations

\begin{tabular}{|c|c|}
\hline Society & Recommendation \\
\hline $\begin{array}{l}\text { ACG [28], } \\
2018\end{array}$ & $\begin{array}{l}\text { Moderately to severely active CD and objective evidence of active disease: } \\
\text { (i) Vedolizumab with or without an immunomodulator should be considered for induction of symptomatic remission (strong } \\
\text { recommendation, high level of evidence) } \\
\text { (ii) Vedolizumab should be used for maintenance of remission of vedolizumab-induced remission of CD (conditional recommendation, } \\
\text { moderate level of evidence) }\end{array}$ \\
\hline $\begin{array}{l}\text { ECCO [29], } \\
2020\end{array}$ & $\begin{array}{l}\text { (A) Moderate-to-severe CD with inadequate response to conventional therapy and/or to anti-TNF therapy: } \\
\text { ECCO recommends vedolizumab for induction of response and remission in such patients (strong recommendation, moderate-quality } \\
\text { evidence) } \\
\text { (B) Moderate-to-severe active luminal CD in patients who have previously failed anti-TNF therapy: } \\
\text { ECCO equally suggests the use of either ustekinumab or vedolizumab for treatment (weak recommendation, very low-quality evidence) } \\
\text { (C) Maintenance therapy: } \\
\text { ECCO recommends vedolizumab for maintaining clinical remission in patients with moderate-to-severe CD who achieved remission with } \\
\text { vedolizumab (strong recommendation, moderate-quality evidence) } \\
\text { (D) CD and complex perianal fistula: } \\
\text { Insufficient evidence to recommend the use of vedolizumab for fistula healing (weak recommendation, low-quality evidence) }\end{array}$ \\
\hline BSG [15], 2019 & $\begin{array}{l}\text { Immunomodulator refractory patients: } \\
\text { BSG recommends biological therapy } \\
\text { Choice between anti-TNF therapy, ustekinumab, and vedolizumab should be made on an individual basis (strong recommendation, very } \\
\text { low-quality evidence) } \\
\text { BSG recommends vedolizumab in both anti-TNF-naive and anti-TNF-failed cases } \\
\text { Induction therapy: strong recommendation, moderate-quality evidence } \\
\text { Maintenance therapy: strong recommendation, high-quality evidence } \\
\text { Anti-TNF therapy switch to vedolizumab or ustekinumab: } \\
\text { Choice to use may be made on an individual basis (weak recommendation, very low-quality evidence) } \\
\text { Pretreatment screening and blood monitoring of therapy on vedolizumab should follow recommendations for anti-TNF drugs due to } \\
\text { insufficient long-term safety data to recommend an alternative algorithm (weak recommendation, very low-quality evidence) }\end{array}$ \\
\hline $\begin{array}{l}\text { APAGE [30], } \\
2016\end{array}$ & No recommendation regarding use of vedolizumab in CD \\
\hline
\end{tabular}

\section{Induction Trial}

Cohort 1: 368 patients were randomly assigned to receive vedolizumab or placebo at weeks 0 and 2 .

Cohort 2: 747 patients received open-label vedolizumab at weeks 0 and 2 .

Primary endpoints at week 6: clinical remission (Crohn's disease activity index $[\mathrm{CDAI}] \leq 150$ points) and a CDAI-100 response ( $\geq 100$-point decrease in CDAI); $14.5 \%$ achieved remission on vedolizumab as opposed to $6.8 \%$ on placebo $(p=0.02)$, and a CDAI- 100 response was achieved by $31.3 \%$ treated with vedolizumab versus $25.7 \%$ on placebo $(p=0.23)$.

\section{Maintenance Trial}

Patients from both cohorts who had a clinical response (i.e., $\geq 70$-point decrease in the CDAI score) to vedolizumab at week 6 were randomly assigned in a 1:1:1 ratio to continue in a blinded fashion to receive vedolizumab every 8 weeks, vedolizumab every 4 weeks, or placebo for up to 52 weeks. The primary endpoint was clin- ical remission at week 52, which was achieved in $39 \%$ who received vedolizumab every 8 weeks, $36.4 \%$ who received vedolizumab every 4 weeks, and $21.6 \%$ who received placebo.

\section{GEMINI 3 Trial}

Sands et al. [32] in their placebo-controlled, phase 3, double-blind trial evaluated the efficacy and safety of vedolizumab, as induction therapy in patients with moderately to severely active CD. $75.7 \%$ of the patient cohort had anti-TNF intolerance or failure. The primary endpoint was clinical remission at week 6 , which was seen in $15.2 \%$ in patients on vedolizumab at 0,2 and 6 weeks, versus $12.1 \%$ with placebo $(p=0.453)$. The secondary endpoints were clinical remission at week 10 and a CDAI100 response at weeks 6 and 10. Clinical remission at week 10 was achieved in $26.6 \%$ in the treatment arm, whereas $12.1 \%$ in placebo $(p=0.001)$. The CDAI- 100 response at week 6 was seen in 39.2 and $22.3 \%$ in the treatment and placebo arms, respectively $(p=0.001)$. 
Sands et al. [33] in their post hoc analysis of the GEMINI 2 and 3 trials of 1,476 CD patients have shown clinical remission at week 52 in $48.9 \%$ of TNF naive (vs. $26.8 \%$ placebo). Among patients who were previously unresponsive to anti-TNF agents, clinical remission with vedolizumab and placebo at week 6 was comparable (13.3 vs. $9.7 \%)$. Clinical remission rates at week 10, however, were higher in vedolizumab-treated patients (21.8 vs. $11.0 \%)$. During maintenance also, clinical remission was higher for vedolizumab-treated patients with prior antiTNF failure against placebo at week 52 (27.7 vs. $12.8 \%$ ). These data suggest that though prior anti-TNF agent failure is associated with more refractoriness to induction therapy, possibly requiring a relatively longer treatment period to demonstrate benefit, responders to vedolizum$\mathrm{ab}$ have a durable treatment benefit irrespective of prior anti-TNF exposure.

\section{"Real-World" Experience in CD}

Dulai et al. [34] in their US VICTORY (Vedolizumab for Health OuTComes in InflammatORY Bowel Diseases) Consortium retrospectively assessed the real-world safety and efficacy of vedolizumab in moderate-to-severe CD [34]. Clinical remission, mucosal healing, and deep remission (clinical remission and mucosal healing) at the end of 12 month were 35, 63, and 26\%, respectively. Factors associated with reduced likelihood of achieving clinical remission were previous anti-TNF agent use, history of smoking, active perianal disease, and severe disease activity.

Bressler et al. [35] in their multicountry, retrospective EVOLVE study assessed the effectiveness and safety of vedolizumab compared to anti-TNF agents in real-world biologic-naive $\mathrm{CD}$ patients. Cumulative rates of clinical response, clinical remission, mucosal healing, and dose escalation were similar in both groups at 24 months. Treatment persistence with vedolizumab was significantly greater at 12 and 18 for vedolizumab than anti-TNF exposed patients, but not at 24 months. Observed incidence rates of $\mathrm{CD}$ exacerbations, $\mathrm{CD}$-related surgery, serious adverse events, and serious infections were lower in the vedolizumab group $(p>0.05)$.

The VERSIFY study was the first prospective study to assess endoscopic, radiologic, and histologic healing in patients receiving vedolizumab therapy for moderate-to-severe CD for at least 3 months ( CDAI score of 220-450), a simple endoscopic score for CD (SES-CD) of 7 or more, 1 or more mucosal ulcerations (identified by endoscopy), and failure of conventional therapy) [36]. The primary endpoint was endoscopic remission at week 26 , achieved by $11.9 \%$ of patients, and by week $52,17.9 \%$ of the patients were in endoscopic remission. Secondary endpoints included endoscopic response, radiologic remission, and histologic response. Patients with moderate CD (SES-CD scores, 7-15) achieved better endoscopic remission than patients with severe CD (SES-CD scores above 15) at weeks 26 and 52. Remission by magnetic resonance enterography was seen in $21.9 \%$ of patients at week 26 and in $38.1 \%$ at week 52 . At week 26 and 52, histologic response in the colon and ileum was seen in 24.4 and $28.3 \%$, and 20.5 and $34.3 \%$, respectively.

LOVE-CD (LOw Countries VEdolizumab in CD) Study prospectively evaluated the ability of vedolizum$a b$ to induce endoscopic and histologic remission in patients with active CD (CDAI score $>220$ and mucosal ulcerations on endoscopy) [37]. At weeks 26 and 52, 29 and $31 \%$ were in corticosteroid-free clinical remission (CDAI score <150), respectively. Endoscopic remission (SES-CD score $<4$ ) was seen in 33 and $36 \%$ at weeks 26 and 52. Endoscopic responses (decrease in SES-CD score by $50 \%$ ) occurred in $40 \%$ at week 26 and $45 \%$ at week 52 . Histologic remission at week 26 was observed in $64 \%$ of based on Geboes Score and $66 \%$ based on Robarts Histopathology Index score. Based on multiple studies, predictors of poor response to vedolizumab therapy in patients with $\mathrm{CD}$ are extensive and severe disease [38-41], active perianal disease [38, 41], history of smoking [34, 38, 41], prior anti-TNF exposure [34, $38,41]$, prior surgery [40], high CRP [38, 40, 41], lack of clinical response at week 6 [42], and corticosteroid use at induction [42].

Several systematic reviews, meta-analysis, and prospective and retrospective studies of vedolizumab use in both UC and CD are depicted in Table 4. Dutch Initiative on Crohn's and Colitis (ICC) in its observational prospective study has assessed the efficacy of vedolizumab or ustekinumab in CD patients, who failed antiTNF treatment [43]. After 52 weeks of treatment, ustekinumab-treated patients were more likely to achieve corticosteroid-free clinical remission (HarveyBradshaw Index $\leq 4)$, biochemical remission (C-reactive protein $\leq 5 \mathrm{mg} / \mathrm{L}$ and fecal calprotectin $\leq 50 \mu \mathrm{g} / \mathrm{g}$ ), and combined corticosteroid-free clinical and biochemical remission, compared to vedolizumab. This study is comparable to network meta-analysis by Singh et al. [27], who found ustekinumab to be more effective than vedolizumab in anti-TNF failed cases with moderate-severe UC. 
Table 4. Real-world studies involving both UC and CD patients

\begin{tabular}{|c|c|c|c|c|c|}
\hline Study & Design & Patients & $\begin{array}{l}\text { Biologic exposure } \\
\text { status }\end{array}$ & Endpoint & Efficacy data \\
\hline \multicolumn{6}{|c|}{ Studies involving both UC and CD patients } \\
\hline $\begin{array}{l}\text { SWIBREG: } \\
\text { Eriksson et al. [46] }\end{array}$ & $\begin{array}{l}\text { Prospective multicenter } \\
\text { national registry }\end{array}$ & $\begin{array}{l}\text { CD: } 147 \\
\text { UC: } 92 \\
\text { IBD-U: } 7\end{array}$ & $\begin{array}{l}\text { TNF failure: } \\
86 \%\end{array}$ & $\begin{array}{l}\text { UC clinical remission } \\
\text { CD clinical remission }\end{array}$ & $\begin{array}{l}\text { At median follow-up of } 17 \\
\text { (IQR: } 14-20) \text { months: } \\
\text { CD: } 54 \% \text { (clinical remission) } \\
\text { UC: } 64 \% \text { (clinical remission) }\end{array}$ \\
\hline Shelton et al. [49] & Prospective multicenter & $\begin{array}{l}\text { CD: } 107 \\
\text { UC: } 59 \\
\text { IBD-U: } 6\end{array}$ & $\begin{array}{l}\text { TNF failure: } \\
97.1 \%\end{array}$ & $\begin{array}{l}\text { Clinical response and remission } \\
\text { in } C D \text { and } U C \text { at week } 14\end{array}$ & $\begin{array}{l}\text { At wk 14: } \\
\text { CD: CRes: } 48.9 \% \\
\text { CRem: } 23.9 \% \\
\text { UC: CRes: } 53.9 \% \\
\text { CRem: } 29.3 \%\end{array}$ \\
\hline Stallmach et al. [50] & Prospective multicenter & $\begin{array}{l}\text { CD: } 67 \\
\text { UC: } 60\end{array}$ & $\begin{array}{l}\text { TNF failure: } \\
\text { CD: } 91 \% \\
\text { UC: } 81.7 \%\end{array}$ & $\begin{array}{l}\text { Clinical remission in } \mathrm{CD} \text { and } \\
\mathrm{UC} \text { at week } 54\end{array}$ & $\begin{array}{l}\text { At wk } 54 \text { (clinical } \\
\text { remission): } \\
\text { CD: } 21 \% \\
\text { UC: } 25 \%\end{array}$ \\
\hline Vivio et al. [51] & Prospective single center & $\begin{array}{l}\text { CD: } 30 \\
\text { UC: } 21\end{array}$ & $\begin{array}{l}\text { TNF failure: } \\
\text { CD: } 96.7 \% \\
\text { UC: } 76.2 \%\end{array}$ & $\begin{array}{l}\text { Improvement in CDAI score in } \\
\mathrm{CD} \text { and clinical remission in } \mathrm{UC} \\
\text { at week } 14\end{array}$ & $\begin{array}{l}\text { At wk 14: } \\
\text { CD: improvement in CDAI } \\
\text { score (mean } 35 \text { points, } \\
p=0.04 \text { ) } \\
\text { UC: clinical remission }(55 \%)\end{array}$ \\
\hline
\end{tabular}


Table 4 (continued)

\begin{tabular}{|c|c|c|c|c|c|}
\hline Study & Design & Patients & $\begin{array}{l}\text { Biologic exposure } \\
\text { status }\end{array}$ & Endpoint & Efficacy data \\
\hline $\begin{array}{l}\text { The Cross Pennine } \\
\text { Study: Lenti et al. [52] }\end{array}$ & $\begin{array}{l}\text { Multicenter } \\
\text { retrospective } \\
\text { study }\end{array}$ & $\begin{array}{l}\text { CD: } 135 \\
\text { UC: } 68\end{array}$ & & $\begin{array}{l}\text { CD clinical response or remission } \\
\text { UC clinical response or remission }\end{array}$ & $\begin{array}{l}\text { Wk 14: } \\
\text { UC CRes or CRem: } 91 \% \\
\text { CD CRes or CRem: } 79 \% \\
\text { Wk 52: } \\
\text { UC CRes or CRem: } 83 \% \\
\text { CD CRes or CRem: } 64 \%\end{array}$ \\
\hline
\end{tabular}

CD, Crohn's disease; CDAI, Crohn's Disease Activity Index; CFCR, corticosteroid-free clinical remission; CRem, clinical remission; CRes, clinical response; IBD, inflammatory bowel disease; TNF, tumor necrosis factor; UC, ulcerative colitis.

\section{Vedolizumab in Special Population}

\section{Extraintestinal Manifestations}

Extraintestinal manifestations (EIMs) occur in up to 55\% of patients with $\mathrm{CD}$ and $35 \%$ of patients with UC $[53,54]$.

Primary Sclerosing Cholangitis

In primary sclerosing cholangitis (PSC), hepatic inflammation driven by TNF- $\alpha$ and methylamines in the portal circulation results in aberrant hepatic expression of MAdCAM-1 and the chemokine CCL25 [55]. Expression of MAdCAM-1 leads to enhanced recruitment of $\alpha 4 \beta 7$ and the CCL25 receptor CCR9 $[55,56]$. Due to the expression of MAdCAM-1 receptors in the liver, it was thought that the inhibition of $\alpha 4 \beta 7$ by vedolizumab may have a potential therapeutic role in PSC.

Caron et al. [57] in their retrospective observational multicenter study of 54 patients with IBD + PSC on vedolizumab found no significant difference in decrease of serum alkaline phosphatase concentration of at least $50 \%$ from baseline, nor for aspartate aminotransferase, $\gamma$-glutamyl transferase, and total bilirubin changes at mean follow-up of 19.4 months. In another retrospective single-center study, Tse et al. [58] also found no significant difference in alkaline phosphatase, aspartate aminotransferase, ALT, and bilirubin levels between evaluation at baseline and at 6-8 or 12-14 months. There was also no significant change in radiographic imaging of biliary tree dilatation and strictures. Christensen et al. [59] in their published retrospective multicenter study found no significant difference for all liver tests between baseline and weeks 14 and 30 .

Arthralgia/Arthritis

Feagan et al. [60] in their post hoc analysis of all 3 GEMINI trials have found that in patients with CD, ve- dolizumab was significantly less likely than placebo to be associated with new/worsening arthritis/arthralgia; however, similar incidence of sustained resolution of arthritis/arthralgia occurred with vedolizumab and placebo. In CD patients on corticosteroids at baseline, a decrease in corticosteroid dose increased the risk of new/worsening arthritis/arthralgia regardless of treatment, and in those achieving corticosteroid-free status, arthritis/arthralgia was less likely with vedolizumab than with placebo. In patients with UC, vedolizumab and placebo showed similar incidence of new/worsening of arthritis/arthralgia. In UC patients on corticosteroids at baseline, arthritis/arthralgia was more likely in those achieving corticosteroid-free status than in those continuing corticosteroids, and in those achieving corticosteroid-free status, the incidence of arthritis/arthralgia was similar with vedolizumab and placebo. $\mathrm{Pa}$ tients with prior anti-TNF exposure were more likely to experience new or worsening arthritis/arthralgia than patients who were anti-TNF naive. Tadbiri et al. [61] in their nested multicenter cohort study of vedolizumab in IBD found that at 54 weeks, patients in remission were more likely to achieve rheumatological remission, as were patients treated for $<3.5$ months after appearance of EIMs.

Incidence of EIMs during Vedolizumab Therapy

Compared with patients on anti-TNFs, CD patients treated with vedolizumab were more likely to develop EIM, specifically erythema nodosum, aphthous stomatitis, episcleritis/scleritis, arthropathy, PSC, and uveitis/iritis [62]. UC patients on vedolizumab did not show any significant increase in the incidence of any EIM compared with patients under anti-TNF agents; however, they were more likely to develop specific EIMs such as aphthous stomatitis, pyoderma gangrenosum, and PSC. 
Systematic review by Chateau et al. [63] concludes that the occurrence of new rheumatic symptoms was lower among vedolizumab users than among placebo. However, occurrence was higher with vedolizumab than with anti-TNF agents, and there is no strong evidence to suggest vedolizumab for the treatment of preexisting EIMs (especially PSC and rheumatic and cutaneous manifestation), although it may reduce the occurrence of new EIMs.

\section{Perianal CD}

Post hoc analysis of the GEMINI 2 trial had shown that at 52 weeks, $41.2 \%$ of 8 -weekly vedolizumab group achieved fistula closure compared with $22.7 \%$ of 4 -weekly group and $11.1 \%$ of the placebo group $(p=0.03, p=$ 0.32 vs. placebo, respectively) [64]. However, conservative interpretation of this borderline significance is warranted due to small numbers and post hoc analysis. Preliminary data from the GEMINI-LTS extension study report a higher incidence (2\%) of new perianal abscess formation among vedolizumab-treated patients with CD [65].

The GETAID BioLAP Study Group in its nationwide multicenter cohort study has assessed the efficacy of vedolizumab in patients with active perianal CD [66]. At median follow-up of 52 weeks, vedolizumab clinical success (defined by no draining fistula at clinical examination and no anal ulcers for primary lesions at 6 months without medical or surgical treatment) was reached in only $22.5 \%$. Moreover, nearly one-third of patients with inactive perianal CD had perianal recurrence on vedolizumab treatment. Prospective data on the efficacy of vedolizumab in perianal CD are currently limited.

\section{Postoperative Complications}

Few retrospective studies by Lightner et al. [67] in adult and pediatric cohort of IBD patients on vedolizumab undergoing surgeries have suggested an increase in postoperative complications and surgical site infections [68]. However, meta-analysis by Law et al. [69] does not support the same. In the GEMINI trials, rate of surgery (vedolizumab: $3.6 \%$, placebo: $2.4 \%$ ), postoperative complications (vedolizumab: 5.9\%; placebo: $14.3 \%$ ), and serious postoperative complications (vedolizumab: $2.0 \%$; placebo: $14.3 \%$ ) were similar. It is likely that the differences in risk estimates suggesting the increased risk in observational studies were driven by inability to control for confounders such as corticosteroid exposure and disease activity [70].

\section{Postoperative Recurrence Risk Reduction}

The effectiveness in preventing postoperative recurrence is unknown. In retrospective study of patients who underwent $C D$-related surgery, it was found that the rate of endoscopic remission at 6-12 months in the vedolizumab group was $25 \%$, which was significantly lower than that in the anti-TNF group $(66 \%, p=0.01)$ [71]. Further prospective multicenter studies are urgently needed.

\section{Refractory Pouchitis of the Ileo-Anal Pouch}

Inflammation of the pouch after ileal pouch-anal anastomosis significantly impact quality of life and is difficult to treat. Multiple case series and case reports along with retrospective multicenter U.S. cohort have found vedolizumab to be effective in such cases [72].

\section{Children}

Although children $<18$ years old were excluded from the registration trials, post-marketing case series demonstrated the safety of vedolizumab in children [73]. In a recent large multicenter case series by ESPGHAN, no serious drug-related adverse events were reported in children with mean age 14.5 (range $2-18$ ) years at a median follow-up of 24 (IQR 14-38, range 6-116) weeks [74].

\section{Elderly}

Post hoc analysis of the GEMINI 1 and 2 trials revealed $11 \%$ were $>55$ years old. Safety profile was similar across all age groups for vedolizumab and placebo [75]. Navaneethan et al. [76] in their single-center, retrospective study showed that vedolizumab is safe and efficacious in patients who were $>60$ years old. Forty-one percent achieved clinical remission at week 52, while $14 \%$ developed pneumonia, Clostridioides difficile infection, and flu-like symptoms.

\section{Pregnancy and Lactation}

Since MAdCAM-1 is expressed in the human placenta during the first trimester of pregnancy, concerns have been raised about a theoretical risk of early miscarriage with the use of vedolizumab during conception and pregnancy [77]. Notably, with a half-life of 25 days, withholding vedolizumab in the third trimester may result in vedolizumab exposure to the fetus with prolonged drug clearance likely up to 6-12 months [70]. The consequences of such fetal exposure are unknown. It is plausible that this may have implications for vaccination against intestinal infections such as rotavirus (which is an oral vaccine), but unlikely with parenteral agents that are administered in the first year of life.
Debnath/Rathi 
Moens et al. [78] have reported several pregnancy and neonatal complications among small set of patients treated with vedolizumab in retrospective Belgian study in form of hip dysplasia, pulmonary valve stenosis, and Hirschsprung's disease. However, the European CONCEIVE study by Moens et al. [79] found no significant difference in miscarriage rates between groups who received vedolizumab and anti-TNF and who were not exposed to immunomodulator or biologics. Prematurity and frequency of congenital anomalies were similar in all the groups.

\section{Safety Data}

The contraindications to vedolizumab use are active tuberculosis (TB), sepsis, or opportunistic infections, including gut infections such as C. difficile [15]. Pretreatment screening is similar to that of anti-TNF treatment. Latent TB should be treated prior to commencing the drug. Patients should be up to date with vaccination prior to starting treatment where possible. Non-live vaccines may be administered during either drug treatment, but not live vaccines. Integrated long-term safety data showed that serious C. difficile infections, sepsis, or TB occurred in $0.6 \%$ of patients, with no cases of progressive multifocal leukoencephalopathy $[80,81]$. Few other studies show no increase in infection risk $[82,83]$. A meta-analysis of 49 studies of biologics with safety data in IBD did show that there is an increase in risk of opportunistic infections, that is, no difference between anti-TNF and antiintegrin agents. Long-term safety data for vedolizumab over 9 years are reassuring [84].

\section{Infection}

This is a major issue in countries where infectious disease like TB is endemic and anti-TNFa agents, which are currently available, pose a serious threat. Agarwal et al. [85] reported active TB in $11.6 \%$ of patients with IBD on Infliximab, within a median follow-up duration of 19 months, whereas, Puri et al. [86] reported an incidence of TB in $8.8 \%$ of their UC patients on Infliximab, within median duration of 8 weeks from 3 referral IBD centers. However, with vedolizumab, nasopharyngitis was the most common adverse event reported, which was comparable to placebo [87]. Independent risk factors for serious infection for UC included prior anti-TNF therapy and narcotics use. For CD, younger age and concomitant steroid and narcotic use were predictors of serious infection [80]. In a systematic review and network meta-analysis,
Singh et al. [27] explored that among biologics, vedolizumab had lowest risk of infections followed by ustekinumab in maintenance trials.

\section{Drawbacks of Vedolizumab}

Slow Onset of Action

As vedolizumab acts by a unique mechanism of inhibiting lymphocyte trafficking rather than directly inhibiting cytokine activity, clinical response is slower in comparison with anti-TNF therapies. Post hoc analysis of GEMINI 2 trial revealed CD patients who received corticosteroid with vedolizumab or a combination of corticosteroid, immunomodulator, and vedolizumab at baseline were more likely to be in clinical remission at week 6 in comparison with patients who received vedolizumab alone or in combination with immunomodulator [88]. However, a similar benefit was not observed in UC patients in post hoc analysis of GEMINI 1 trial [89].

Vedolizumab combination with calcineurin inhibitors, cyclosporine or tacrolimus, has been tried by Pellet et al. [90] in their retrospective study of patients with refractory UC on maintenance therapy with vedolizumab. Colectomy-free survival at 1 year was $68 \%$. Similarly, Christensen et al. [91] have studied the efficacy of same combination therapy in patients with refractory UC and CD. At 52 weeks of treatment, $33 \%$ of CD and $45 \%$ of UC were in steroid-free clinical remission. Thus, combination therapy of vedolizumab with either cyclosporine or tacrolimus is effective at inducing and maintaining clinical remission in patients with CD and UC with up to 52 weeks of follow-up evaluation.

\section{Cost-Effectiveness}

In countries like India and other Asian countries, it is very important to consider cost-effectiveness of the drug used. As vedolizumab is recently launched in India along with other Asian countries, it is priced almost double that of infliximab (Remicade), whereas two and half times that of infliximab biosimilar, which is also having the same dosing schedule. Limited data exist on the cost-effectiveness of vedolizumab as a first-line biologic treatment in patients with IBD.

\section{Evolving Paradigms}

\section{Therapeutic Drug Monitoring}

Therapeutic drug monitoring (TDM) has been recognized as an important strategy to inform clinical decisionmaking in patients with IBD $[5,92,93]$. The rationale for 
TDM is that systematic and algorithmic assessment of drug concentration and ADAs may help objectively evaluate potential reasons for failure of therapy and define next steps in management and proactively provide opportunities for optimizing therapy. While TDM has been extensively studied and implemented when using antiTNF $\alpha$ agents, its role in the optimization of vedolizumab is unclear. The recent AGA guidelines and the Sydney IBD Consensus statements on TDM focused only on anti-TNFa agents [92, 94]. The BRIDGe group recommended the use of TDM in vedolizumab-treated patients with primary nonresponse or secondary loss of response primarily to determine the presence or absence of drug but could not recommend optimal trough concentrations [93]. Post hoc analysis of the GEMINI trials demonstrated that higher trough levels correlated with higher rates of clinical remission. Induction trough levels of $<17 \mu \mathrm{g} /$ $\mathrm{mL}$ for $\mathrm{UC}$ and $<16 \mu \mathrm{g} / \mathrm{mL}$ for $\mathrm{CD}$ were associated with remission rates similar to placebo [95]. Further analysis of UC patients from the GEMINI study revealed target levels of $37.1 \mu \mathrm{g} / \mathrm{mL}$ at week 6 during induction, $18.4 \mu \mathrm{g} /$ $\mathrm{mL}$ at week 14 and $12.7 \mu \mathrm{g} / \mathrm{mL}$ during maintenance [96].

Systematic review with meta-analysis by Singh et al. [97] found that vedolizumab trough concentration $>20$ $\mu \mathrm{g} / \mathrm{mL}$ at week 6 and $>12 \mu \mathrm{g} / \mathrm{mL}$ during maintenance may be associated with better clinical outcomes. However, in patients with $\mathrm{CD}$, there was no significant difference in median vedolizumab trough concentrations in patients achieving clinical remission or endoscopic remission. Lowenberg et al. [37] in their prospective study found that serum concentration of vedolizumab above $10 \mathrm{mg} / \mathrm{L}$ at week 22 was associated with endoscopic remission at week 26. Factors associated with low vedolizumab trough levels with worse therapeutic outcomes are low serum albumin, high BMI, high CRP, and low hemoglobin $[95,98,99]$.

\section{Immunogenicity}

Pooled analysis of GEMINI data revealed ADAs in 4\% of patients [80]. Moreover, Singh et al. [97] in their systematic review and meta-analysis also found ADAs in $1.7-3 \%$ of patients on maintenance therapy. This corroborates with the observation that the addition of an immunomodulator neither enhances drug levels nor improves therapeutic response, and the ability to use vedolizumab as monotherapy may be advantageous in certain patient groups.

\section{Vedolizumab as Dual Biologic Therapy}

Vedolizumab in combination with anti-TNF or ustekinumab was found to be effective in patients with both UC and CD in a systematic review with pool analysis by Ribaldone et al. [100]. Clinical improvement was seen in $100 \%$ patients and endoscopic improvement in $93 \%$. This is in contrast to the findings by Yang et al. [101], where dual biologic therapy in various combination in patients with refractory CD was found to have endoscopic improvement in 63\% (vedolizumab + ustekinumab) and $33 \%$ (vedolizumab + anti-TNF) and clinical response in $71 \%$ (vedolizumab + ustekinumab) and $42 \%$ (vedolizumab + anti-TNF agent).

\section{Efficacy Data from the East}

In a phase 3 trial of moderate-severe UC patients from Japan, Motoya et al. [102] have found vedolizumab to be effective as maintenance therapy but not as induction therapy compared to placebo. Similarly, in moderate-tosevere CD Japanese patients, vedolizumab was not found to be better than placebo at both 10 weeks (CDAI-100 response) and 60 weeks (clinical remission) [103]. However, data from post hoc analysis of UC patients in the GEMINI 1 trial from Asian countries have shown efficacy and safety of vedolizumab to be broadly consistent with that of overall study population [104]. Moreover, pharmacokinetic profile of vedolizumab was found to be similar between Asians and non-Asian moderate-to-severe $\mathrm{UC}$ and CD, thus supporting the use of vedolizumab flatfixed dosing in Asian patients as well [105].

The Asia Pacific Association of Gastroenterology (APAGE) Working Group on IBD is yet to incorporate use of vedolizumab in moderate-severe $\mathrm{UC}$ or $\mathrm{CD}[16$, 30]. Also, recent clinical practice guidelines for IBD by the Japanese Society of Gastroenterology did not make any recommendation regarding the use of vedolizumab [106]. However, latest APAGE guidelines on IBD management during the COVID-19 pandemic mention the use of vedolizumab and ustekinumab in patients requiring initiation of biologic agents due to their less systemic immunosuppressive activity [107]. Moreover, vedolizumab and ustekinumab may also be preferred in higher risk elderly individuals.

\section{Predictors of Response}

Soendergaard et al. [108] in their retrospective study have studied the circulating inflammatory cytokine pattern among patients failing consecutive anti-TNF and vedolizumab to identify predictors of response. Circulating interleukin-6 was significantly higher in anti-TNF and vedolizumab nonresponders than in vedolizumab responders. CD patients with higher soluble CD40 ligand (sCD40L) responded poorly to treatment, whereas
12

Inflamm Intest Dis 2021;6:1-17 DOI: $10.1159 / 000512805$
Debnath/Rathi 
Fig. 1. The use of vedolizumab and specific advantages of anti-TNF agent and vedolizumab in patients with IBD. IBD, inflammatory bowel disease.

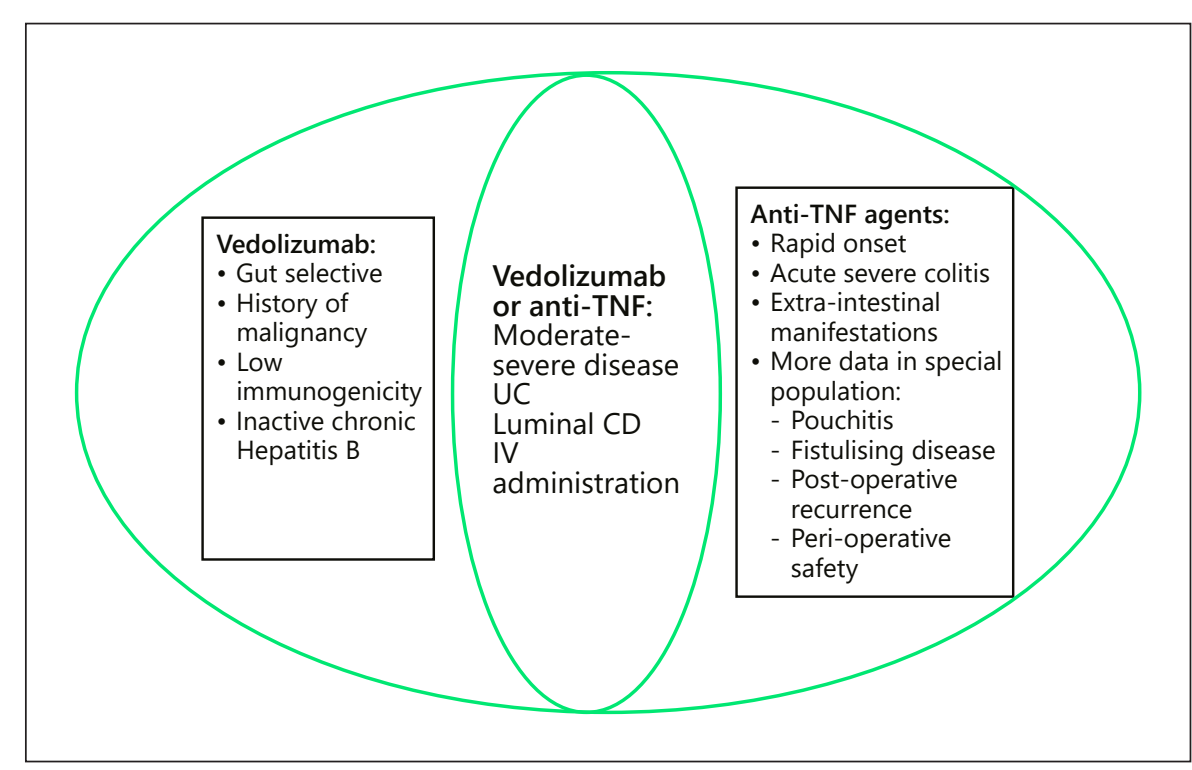

in UC patients, osteocalcin was higher among patients responding to Vedolizumab. Boden et al. [109] have found pretreatment $\alpha 4 \beta 7$ expression and $\alpha 4 \beta 7$ receptor saturation during maintenance therapy as candidate biomarkers for vedolizumab response. Moreover, during therapy, $\log 10$ serum vedolizumab levels were higher and the percentage of effector memory $\mathrm{T}$ cells with free $\alpha 4 \beta 7$ at trough was lower in responders than in nonresponders.

Both of these studies focused only on predictors of clinical response, and as targets in IBD are evolving from clinical to endoscopic remission, biomarker development should focus on the prediction of endoscopic remission. Verstockt et al. [110] have studied colonic transcriptomic data on biopsies of IBD patients initiating vedolizumab and searched for predictive markers of vedolizumab-specific endoscopic remission. They have identified and validated 4 genes (PIWIL1, MAATS1, RGS13, and DCHS2) whose baseline expression levels in colon tissues of patients with IBD associate with endoscopic remission after vedolizumab but not anti-TNF treatment. Paul et al. [111] found that high pretreatment serum retinoic acid levels were predictive of achieving clinical remission and undetectable levels of soluble MAdCAM-1 (s-MAdCAM-1) in maintenance therapy were strongly associated with clinical remission. Soluble $\alpha 4 \beta 7$, soluble VCAM, and soluble TNF may also help to predict the achievement of endpoints (clinical or endoscopic remission) during treatment [112].

Vedolizumab Use in IBD

\section{Unresolved Issues}

In view of its excellent safety and efficacy data, guidelines from all major societies advise the use of vedolizumab in cases of steroid-dependent, steroid-refractory, moderate-severe cases of UC and CD. However, there are few issues that are still unexplored in this field, which are discussed below:

1. Whether TDM is to be considered in patients with IBD on vedolizumab?

2. When is TDM advised in patients on vedolizumab?

a. In responders at the end of induction.

b. During maintenance for patients on vedolizumab in proactive fashion.

c. In nonresponders at the end of induction.

d. In patients with confirmed secondary loss of response.

3. The efficacy of vedolizumab has not been formally tried in cases of acute severe UC in randomized trials. Future trials can look for its efficacy in anti-TNF failed cases of acute severe UC.

4. The risk of infectious diseases like $\mathrm{TB}$ in endemic countries is yet to be explored with vedolizumab use.

\section{Conclusion}

The landscape of biologic therapies for IBD has changed dramatically over the past decade with the widespread introduction of less-expensive infliximab and adalimumab biosimilars, as well as vedolizumab, oral Janus kinase inhibitor (tofacitinib), and ustekinumab, that 
biologics rather than hospitalization or colectomy are now the main driver of health-care costs in management [113].

Factors to be considered before choosing a biologic, immunosuppressive, or immunomodulator therapy are as follows:

- Patient disease phenotype.

- Biologic naive or exposed.

- Route of administration (oral, subcutaneous, intramuscular, and intravenous).

- Speed of response to induction therapy (consider need for bridging therapy).

- Potential immunogenicity and need for combination therapy.

- Side effects including risk of malignancy.

- Persistence (continuing drug without loss of response after initial improvement).

- Overall cost (including drug delivery and monitoring). Figure 1 depicts the strength and limitations of currently available biologics for use in IBD in India and other developing countries. Based on various guidelines, real-world data of its safety and efficacy and taking into consideration cost issue, vedolizumab may be considered in the following conditions:

1. Primary or secondary loss of response to anti-TNF agents based on drug trough level and ADA level.

2. Patients with evidence of latent TB: though studies from India did not show reactivation of TB in patients with latent $\mathrm{TB}$ who were started on infliximab or adalimumab, various studies from outside India have docu- mented $\mathrm{TB}$ reactivation in patients with latent $\mathrm{TB}$ on anti-TNF therapy $[114,115]$.

3. Patients with inactive chronic hepatitis B: infliximab is associated with high risk of reactivation $(>10 \%)$ in patients with HBsAg-positive inactive chronic Hepatitis $\mathrm{B}$ and moderate risk of reactivation $(1-10 \%)$ in HbsAg-negative, anti-HBc-positive patients [116]. However, data on vedolizumab show that it is much safer as no cases of reactivation have been observed in clinical trials or post-marketing setting.

4. Patients intolerant to or have contraindications to thiopurine use.

5. Rarely, in patients with concomitant malignancy (leukemia, lymphoma, melanoma, etc.)

\section{Conflict of Interest Statement}

There are no conflicts of interest.

\section{Funding Sources}

The authors did not receive any funding.

\section{Author Contributions}

P.D.: preparation and writing the original draft. P.M.R.: critical revision and final approval of the manuscript.

\section{References}

1 Colombel JF, Narula N, Peyrin-Biroulet L. Management strategies to improve outcomes of patients with inflammatory bowel diseases. Gastroenterology. 2017;152(2):351-61.e5.

2 Bouguen G, Peyrin-Biroulet L. Surgery for adult Crohn's disease: what is the actual risk? Gut. 2011;60:1178-81.

3 Khanna R, Bressler B, Levesque BG, Zou G, Stitt LW, Greenberg GR, et al. Early combined immunosuppression for the management of Crohn's disease (REACT): a cluster randomised controlled trial. Lancet. 2015;386: 1825-34.

4 Targan SR, Hanauer SB, van Deventer SJ, Mayer L, Present DH, Braakman T, et al. A short-term study of chimeric monoclonal antibody cA2 to tumor necrosis factor alpha for Crohn's disease. Crohn's Disease cA2 Study Group. N Engl J Med. 1997;337(15):1029-35.
5 Khanna R, Sattin BD, Afif W, Benchimol EI Bernard EJ, Bitton A, et al. Review article: a clinician's guide for therapeutic drug monitoring of infliximab in inflammatory bowel disease. Aliment Pharmacol Ther. 2013;38: 447-59.

6 Sandborn WJ, Feagan BG, Rutgeerts P, Hanauer S, Colombel JF, Sands BE, et al. Vedolizumab as induction and maintenance therapy for Crohn's disease. N Engl J Med. 2013;369(8):711-21

7 Thomas S, Baumgart DC. Targeting leukocyte migration and adhesion in Crohn's disease and ulcerative colitis. Inflammopharmacology. 2012;20(1):1-18.

8 Rogler G. Mechanism of action of vedolizumab: do we really understand it? Gut. 2019 Jan 1;68(1):4-5.
9 Feagan BG, Greenberg GR, Wild G, Fedorak RN, Paré P, McDonald JW, et al. Treatment of active Crohn's disease with MLN0002, a humanized antibody to the alpha4beta7 integrin. Clin Gastroenterol Hepatol. 2008;6(12): $1370-7$.

10 Feagan BG, Greenberg GR, Wild G, Fedorak RN, Paré P, McDonald JW, et al. Treatment of ulcerative colitis with a humanized antibody to the alpha4beta7 integrin. $\mathrm{N}$ Engl J Med. 2005;352(24):2499-507.

11 Zeissig S, Rosati E, Dowds CM, Aden K, Bethge J, Schulte B, et al. Vedolizumab is associated with changes in innate rather than adaptive immunity in patients with inflammatory bowel disease. Gut. 2019;68(1):25-39.

12 Rubin DT, Ananthakrishnan AN, Siegel CA, Sauer BG, Long MD. ACG clinical guideline: ulcerative colitis in adults. Am J Gastroenterol. 2019 Mar 1;114(3):384-413. 
13 Harbord M, Eliakim R, Bettenworth D, Karmiris K, Katsanos K, Kopylov U, et al. Third European evidence-based consensus on diagnosis and management of ulcerative colitis. Part 2: current management. J Crohns Colitis. 2017 Jul 1;11(7):769-84.

14 Feuerstein JD, Isaacs KL, Schneider Y, Siddique SM, Falck-Ytter Y, Singh S, et al. AGA clinical practice guidelines on the management of moderate to severe ulcerative colitis. Gastroenterology. 2020 Apr;158(5):1450-61.

15 Lamb CA, Kennedy NA, Raine T, Hendy PA, Smith PJ, Limdi JK, et al. British Society of Gastroenterology consensus guidelines on the management of inflammatory bowel disease in adults. Gut. 2019 Dec 1;68(Suppl 3):s1-06.

16 Ooi CJ, Fock KM, Makharia GK, Goh KL, Ling KL, Hilmi I, et al. The Asia-Pacific consensus on ulcerative colitis. J Gastroenterol Hepatol. 2010 Mar;25(3):453-68.

17 Feagan BG, Rutgeerts P, Sands BE, Hanauer S, Colombel JF, Sandborn WJ, et al. Vedolizumab as induction and maintenance therapy for ulcerative colitis. N Engl J Med. 2013; 369(8):699-710.

18 Loftus EV Jr, Colombel JF, Feagan BG, Vermeire S, Sandborn WJ, Sands BE, et al. Longterm efficacy of vedolizumab for ulcerative colitis. J Crohns Colitis. 2017;11(4):400-11.

19 Feagan BG, Lasch K, Lissoos T, Cao C, Wojtowicz AM, Khalid JM, et al. Rapid response to vedolizumab therapy in biologic-naive patients with inflammatory bowel diseases. Clin Gastroenterol Hepatol. 2019;17(1):130-8.e7.

20 Mosli MH, MacDonald JK, Bickston SJ, Behm BW, Tsoulis DJ, Cheng J, et al. Vedolizumab for induction and maintenance of remission in ulcerative colitis: a Cochrane systematic review and meta-analysis. Inflamm Bowel Dis. 2015;21(5):1151-9.

21 Narula N, Peerani F, Meserve J, Kochhar G, Chaudrey K, Hartke J, et al. Vedolizumab for ulcerative colitis: treatment outcomes from the VICTORY consortium. Am J Gastroenterol. 2018;113(9):1345.

22 Yarur A, Mantzaris G, Silverberg M, Walshe M, Zezos P, Stein D, et al. P573 Real-world effectiveness and safety of vedolizumab and anti-TNF in biologic-naive ulcerative colitis patients: results from the EVOLVE study. J Crohns Colitis. 2019;13(Suppl 1):S400-1.

23 Sands BE, Peyrin-Biroulet L, Loftus EV Jr, Danese S, Colombel JF, Törüner M, et al. Vedolizumab versus adalimumab for moderateto-severe ulcerative colitis. N Engl J Med. 2019;381(13):1215-26.

24 Singh S, Fumery M, Sandborn WJ, Murad MH. Systematic review with network metaanalysis: first- and second-line pharmacotherapy for moderate-severe ulcerative colitis. Aliment Pharmacol Ther. 2018;47(2):162-75.

25 Bonovas S, Lytras T, Nikolopoulos G, PeyrinBiroulet L, Danese S. Systematic review with network meta-analysis: comparative assessment of tofacitinib and biological therapies for moderate-to-severe ulcerative colitis. Aliment Pharmacol Ther. 2018;47(4):454-65.
26 Farrell RJ. Biologics beyond anti-TNF agents for ulcerative colitis: efficacy, safety, and cost? N Engl J Med. 2019;381(13):1279-81.

27 Singh S, Murad MH, Fumery M, Dulai PS, Sandborn WJ. First- and second-line pharmacotherapies for patients with moderate to severely active ulcerative colitis: an updated network meta-analysis. Clin Gastroenterol Hepatol. 2020 Jan 13

28 Lichtenstein GR, Loftus EV, Isaacs KL, Regueiro MD, Gerson LB, Sands BE. ACG clinical guideline: management of Crohn's disease in adults. Am J Gastroenterol. 2018 Apr 1; 113(4):481-517.

29 Torres J, Bonovas S, Doherty G, Kucharzik T, Gisbert JP, Raine T, et al. ECCO guidelines on therapeutics in Crohn's disease: medical treatment. J Crohns Colitis. 2020 Jan 1;14(1): 4-22.

30 Ooi CJ, Makharia GK, Hilmi I, Gibson PR, Fock KM, Ahuja V, et al. Asia-Pacific consensus statements on Crohn's disease. Part 2: management. J Gastroenterol Hepatol. 2016 Jan;31(1):56-68.

31 Sandborn WJ, Feagan BG, Rutgeerts P, Hanauer S, Colombel JF, Sands BE, et al. Vedolizumab as induction and maintenance therapy for Crohn's disease. N Engl J Med. 2013;369(8):711-21.

32 Sands BE, Feagan BG, Rutgeerts P, Colombel JF, Sandborn WJ, Sy R, et al. Effects of vedolizumab induction therapy for patients with Crohn's disease in whom tumor necrosis factor antagonist treatment failed. Gastroenterology. 2014;147(3):618-e3.

33 Sands BE, Sandborn WJ, Van Assche G, Lukas $\mathrm{M}, \mathrm{Xu}$ J, James A, et al. Vedolizumab as induction and maintenance therapy for Crohn's disease in patients naïve to or who have failed tumor necrosis factor antagonist therapy. Inflamm Bowel Dis. 2017;23(1):97-106.

34 Dulai PS, Singh S, Jiang X, Peerani F, Narula $\mathrm{N}$, Chaudrey K, et al. The real-world effectiveness and safety of vedolizumab for moderatesevere Crohn's disease: results from the US VICTORY consortium. Am J Gastroenterol. 2016;111(8):1147-55.

35 Bressler B, Mantzaris G, Silverberg M, Zezos P, Stein D, Colby C, et al. P621 real-world effectiveness and safety of vedolizumab and anti-TNF in biologic-naive Crohn's disease patients: results from the EVOLVE study. J Crohns Colitis. 2019;13(Suppl 1):S427-8.

36 Danese S, Sandborn WJ, Colombel JF, Vermeire S, Glover SC, Rimola J, et al. Endoscopic, radiologic, and histologic healing with vedolizumab in patients with active Crohn's disease. Gastroenterology. 2019;157(4):1007-18. e7.

37 Lowenberg M, Vermeire S, Mostafavi N, Hoentjen F, Franchimont D, Bossuyt P, et al. Vedolizumab induces endoscopic and histologic remission in patients with Crohn's disease. Gastroenterology. 2019;157(4):9971006.
38 Engel T, Ungar B, Yung DE, Ben-Horin S, Eliakim R, Kopylov U. Vedolizumab in IBDlessons from real-world experience; a systematic review and pooled analysis. J Crohns Colitis. 2018;12(2):245-57.

39 Kopylov U, Verstockt B, Biedermann L, Sebastian S, Pugliese D, Sonnenberg E, et al. Effectiveness and safety of vedolizumab in antiTNF-naïve patients with inflammatory bowel disease-a multicenter retrospective European study. Inflamm Bowel Dis. 2018;24(11): 2442-51.

40 Chaparro M, Garre A, Ricart E, Iborra M, Mesonero F, Vera I, et al. Short and long-term effectiveness and safety of vedolizumab in inflammatory bowel disease: results from the ENEIDA registry. Aliment Pharmacol Ther. 2018;48(8):839-51.

41 Barre A, Colombel JF, Ungaro R. Review article: predictors of response to vedolizumab and ustekinumab in inflammatory bowel disease. Aliment Pharmacol Ther. 2018;47(7): 896-905

42 Amiot A, Grimaud JC, Peyrin-Biroulet L, Filippi J, Pariente B, Roblin X, et al. Effectiveness and safety of vedolizumab induction therapy for patients with inflammatory bowel disease. Clin Gastroenterol Hepatol. 2016; 14(11):1593-e2.

43 Biemans VBC, van der Woude CJ, Dijkstra G, van der Meulen-de Jong AE, Löwenberg $M$, de Boer NK, et al. Ustekinumab is associated with superior effectiveness outcomes compared to vedolizumab in Crohn's disease patients with prior failure to anti-TNF treatment. Aliment Pharmacol Ther. 2020;52(1): 123-34.

44 Schreiber S, Dignass A, Peyrin-Biroulet L, Hather G, Demuth D, Mosli M, et al. Systematic review with meta-analysis: real-world effectiveness and safety of vedolizumab in patients with inflammatory bowel disease. J Gastroenterol. 2018;53(9):1048-64.

45 Engel T, Ungar B, Yung DE, Ben-Horin S, Eliakim R, Kopylov U. Vedolizumab in IBDlessons from real-world experience; a systematic review and pooled analysis. J Crohns Colitis. 2018;12(2):245-57.

46 Eriksson C, Marsal J, Bergemalm D, Vigren L, Björk J, Eberhardson M, et al. Long-term effectiveness of vedolizumab in inflammatory bowel disease: a national study based on the Swedish National Quality Registry for Inflammatory Bowel Disease (SWIBREG). Scand J Gastroenterol. 2017;52(6-7):722-9.

47 Amiot A, Serrero M, Peyrin-Biroulet L, Filippi J, Pariente B, Roblin X, et al. One-year effectiveness and safety of vedolizumab therapy for inflammatory bowel disease: a prospective multicentre cohort study. Aliment Pharmacol Ther. 2017;46(3):310-21.

48 Kopylov U, Ron Y, Avni-Biron I, Koslowsky B, Waterman M, Daher S, et al. Efficacy and safety of vedolizumab for induction of remission in inflammatory bowel disease-the Israeli real-world experience. Inflamm Bowel Dis. 2017;23(3):404-8. 
49 Shelton E, Allegretti JR, Stevens B, Lucci M, Khalili H, Nguyen DD, et al. Efficacy of vedolizumab as induction therapy in refractory IBD patients: a multicenter cohort. Inflamm Bowel Dis. 2016;21(12):2879-85.

50 Stallmach A, Langbein C, Atreya R, Bruns T, Dignass A, Ende K, et al. Vedolizumab provides clinical benefit over 1 year in patients with active inflammatory bowel disease: a prospective multicenter observational study. Aliment Pharmacol Ther. 2016;44(11-12): 1199-212.

51 Vivio EE, Kanuri N, Gilbertsen JJ, Monroe K, Dey $\mathrm{N}$, Chen $\mathrm{CH}$, et al. Vedolizumab effectiveness and safety over the first year of use in an IBD clinical practice. J Crohns Colitis. 2016;10(4):402-9.

52 Lenti MV, Levison S, Eliadou E, Willert R, Kemp K, Carter A, et al. A real-world, longterm experience on effectiveness and safety of vedolizumab in adult patients with inflammatory bowel disease: the Cross Pennine study. Dig Liver Dis. 2018;50(12):1299-304.

53 Zippi M, Corrado C, Pica R, Avallone EV, Cassieri C, De Nitto D, et al. Extraintestinal manifestations in a large series of Italian inflammatory bowel disease patients. World $\mathrm{J}$ Gastroenterol. 2014;20(46):17463-7.

54 Ott C, Schölmerich J. Extraintestinal manifestations and complications in IBD. Nat Rev Gastroenterol Hepatol. 2013;10(10):585-95.

55 Hirschfield GM, Karlsen TH, Lindor KD, Adams DH. Primary sclerosing cholangitis. Lancet. 2013;382(9904):1587-99.

56 Miles A, Liaskou E, Eksteen B, Lalor PF, Adams DH. CCL25 and CCL28 promote alpha4 beta7-integrin-dependent adhesion of lymphocytes to MAdCAM-1 under shear flow. Am J Physiol Gastrointest Liver Physiol. 2008; 294(5):G1257-67.

57 Caron B, Peyrin-Biroulet L, Pariente B, Bouhnik Y, Seksik P, Bouguen G, et al. Vedolizumab therapy is ineffective for primary sclerosing cholangitis in patients with inflammatory bowel disease: a GETAID multicentre cohort study. J Crohns Colitis. 2019 Sep 27;13(10): 1239-47.

58 Tse CS, Loftus EV, Raffals LE, Gossard AA, Lightner AL. Effects of vedolizumab, adalimumab and infliximab on biliary inflammation in individuals with primary sclerosing cholangitis and inflammatory bowel disease. Aliment Pharmacol Ther. 2018;48(2):190-5.

59 Christensen B, Gibson PR, Rubin DT. Letter: vedolizumab for autoimmune liver disease associated inflammatory bowel disease: authors' reply. Aliment Pharmacol Ther. 2018; 47:1423-4.

60 Feagan BG, Sandborn WJ, Colombel JF, Byrne SO, Khalid JM, Kempf C, et al. Incidence of arthritis/arthralgia in inflammatory bowel disease with long-term vedolizumab treatment: post hoc analyses of the GEMINI trials. J Crohns Colitis. 2019;13:50-7.

61 Tadbiri S, Peyrin-Biroulet L, Serrero M, Filippi J, Pariente B, Roblin X, et al. Impact of vedolizumab therapy on extra-intestinal mani- festations in patients with inflammatory bowel disease: a multicentre cohort study nested in the OBSERV-IBD cohort. Aliment Pharmacol Ther. 2018;47(4):485-93.

62 Dubinsky MC, Cross RK, Sandborn WJ, Long M, Song X, Shi N, et al. Extraintestinal manifestations in vedolizumab and anti-TNFtreated patients with inflammatory bowel disease. Inflamm Bowel Dis. 2018 Aug 16;24(9): 1876-82.

63 Chateau T, Bonovas S, Le Berre C, Mathieu N, Danese S, Peyrin-Biroulet L. Vedolizumab treatment in extra-intestinal manifestations in inflammatory bowel disease: a systematic review. J Crohns Colitis. 2019 Dec 10;13(12): 1569-77.

64 Feagan BG, Schwartz DA, Danese S, Rubin D, Abhyankar B, Smyth M, et al. Vedolizumab for the treatment of fistulizing Crohn's disease: an exploratory analysis of data from GEMINI 2. Gastroenterology. 2015;1:S274.

65 Vermeire S, Loftus EV, Colombel JF, Feagan B, Sandborn W, Sands B, et al. Long-term effectiveness and safety of vedolizumab in patients with Crohn's disease: 5-year cumulative exposure of GEMINI 2 completers rolling into the GEMINI open-label extension study. Gastroenterology. 2017;152(5):S601.

66 Chapuis-Biron C, Bourrier A, Nachury M, Nancey S, Bouhnik Y, Serrero M, et al. Vedolizumab for perianal Crohn's disease: a multicentre cohort study in 151 patients. Aliment Pharmacol Ther. 2020 Apr;51(7):71927.

67 Lightner AL, Mathis KL, Tse CS, Pemberton $\mathrm{JH}$, Shen B, Kochhar G, et al. Postoperative outcomes in vedolizumab-treated patients undergoing major abdominal operations for inflammatory bowel disease: retrospective multicenter cohort study. Inflamm Bowel Dis. 2018;24(4):871-6.

68 Lightner AL, Tse CS, Potter DD Jr, Moir C. Postoperative outcomes in vedolizumabtreated pediatric patients undergoing abdominal operations for inflammatory bowel disease. J Pediatr Surg. 2018;53(9):1706-9.

69 Law CCY, Narula A, Lightner AL, McKenna NP, Colombel JF, Narula N. Systematic review and meta-analysis: preoperative vedolizumab treatment and postoperative complications in patients with inflammatory bowel disease. J Crohns Colitis. 2018;12(5):538-45.

70 Crooks B, Barnes T, Limdi JK. Vedolizumab in the treatment of inflammatory bowel disease: evolving paradigms. Drugs Context. 2020;9.

71 Yamada A, Komaki Y, Patel N, Komaki F, Pekow J, Dalal S, et al. The use of vedolizumab in preventing postoperative recurrence of Crohn's disease. Inflamm Bowel Dis. 2018; 24(3):502-9.

72 Gregory M, Weaver KN, Hoversten P, Hicks SB, Patel D, Ciorba MA, et al. Efficacy of vedolizumab for refractory pouchitis of the ileoanal pouch: results from a multicenter US cohort. Inflamm Bowel Dis. 2019;25(9):156976.
73 Conrad MA, Stein RE, Maxwell EC, Albenberg L, Baldassano RN, Dawany N, et al. Vedolizumab therapy in severe pediatric inflammatory bowel disease. Inflamm Bowel Dis. 2016;22(10):2425-31.

74 Ledder O, Assa A, Levine A, Escher JC, De Ridder L, Ruemmele F, et al. Vedolizumab in paediatric inflammatory bowel disease: a retrospective multi-centre experience from the paediatric IBD Porto Group of ESPGHAN. J Crohns Colitis. 2017 Oct 1;11(10):1230-7.

75 Yajnik V, Khan N, Dubinsky M, Axler J, James A, Abhyankar B, et al. Efficacy and safety of vedolizumab in ulcerative colitis and Crohn's disease patients stratified by age. Adv Ther. 2017;34(2):542-59.

76 Navaneethan U, Edminister T, Zhu X, Kommaraju K, Glover S. Vedolizumab is safe and effective in elderly patients with inflammatory bowel disease. Inflamm Bowel Dis. 2017; 23(4):E17.

77 Zelinkova Z, Berakova K, Podmanicky D, Kadleckova B. Placental MADCAM1 expression and potential consequences for the treatment with vedolizumab during pregnancy. Digestive Disease Week, AGA abstract.

78 Moens A, van Hoeve K, Humblet E, Rahier J-F, Bossuyt P, Dewit S, et al. Outcome of pregnancies in female patients with inflammatory bowel diseases treated with vedolizumab. J Crohns Colitis. 2019;13(1):12.

79 Moens A, van der Woude CJ, Julsgaard M, Humblet E, Sheridan J, Baumgart DC, et al. Pregnancy outcomes in inflammatory bowel disease patients treated with vedolizumab, anti-TNF or conventional therapy: results of the European CONCEIVE study. Aliment Pharmacol Ther. 2020;51:129-38.

80 Colombel JF, Sands BE, Rutgeerts P, Sandborn W, Danese S, D'Haens G, et al. The safety of vedolizumab for ulcerative colitis and Crohn's disease. Gut. 2017;66(5):839-51.

81 Jin Y, Lin Y, Lin LJ, Zheng CQ. Meta-analysis of the effectiveness and safety of vedolizumab for ulcerative colitis. World J Gastroenterol. 2015;21(20):6352-60.

82 Luthra P, Peyrin-Biroulet L, Ford AC. Systematic review and meta-analysis: opportunistic infections and malignancies during treatment with antiintegrin antibodies in inflammatory bowel disease. Aliment Pharmacol Ther. 2015;41:1227-36.

83 Ge WS, Fan JG. Integrin antagonists are effective and safe for Crohn's disease: a meta-analysis. World J Gastroenterol. 2015;21:4744-9.

84 Vermeire S, Colombel J-F, Feagan BG, Sandborn WJ, Sands BE, Danese S, et al. OP26 Long-term safety of vedolizumab in ulcerative colitis and Crohn's disease: final results from the GEMINI LTS study. J Crohns Colitis. 2019;13(Suppl 1):S018-20.

85 Agarwal A, Kedia S, Jain S, Gupta V, Bopanna S, Yadav DP, et al. High risk of tuberculosis during infliximab therapy despite tuberculosis screening in inflammatory bowel disease patients in India. Intest Res. 2018 Oct;16(4): 588 . 
86 Puri AS, Desai D, Sood A, Sachdeva S. Infliximab-induced tuberculosis in patients with UC: Experience from India: a country with high prevalence of tuberculosis. J Gastroenterol Hepatol. 2017 Jun;32(6):1191-4.

87 Bye WA, Jairath V, Travis SPL. Systematic review: the safety of vedolizumab for the treatment of inflammatory bowel disease. Aliment Pharmacol Ther. 2017;46(1):3-15.

88 Colombel J-F, Loftus EV, Siegel CA, Lewis J, Smyth MD, Xu J, et al. Sa1270 efficacy of vedolizumab with concomitant corticosteroid or immunomodulator use in patients with Crohn's disease from GEMINI 2. Gastroenterology. 2015;148(4):S-277.

89 Colombel J-F, Loftus EV, Siegel CA, Lewis J, Smyth MD, Sankoh S, et al. Sa1271 efficacy of vedolizumab with concomitant corticosteroid or immunomodulator use in patients with ulcerative colitis from GEMINI 1. Gastroenterology. 2015;148(4):S-277-8.

90 Pellet G, Stefanescu C, Carbonnel F, PeyrinBiroulet L, Roblin X, Allimant C, et al. Efficacy and safety of induction therapy with calcineurin inhibitors in combination with vedolizumab in patients with refractory ulcerative colitis. Clin Gastroenterol Hepatol. 2019 Feb 1;17(3):494-501.

91 Christensen B, Gibson PR, Micic D, Colman RJ, Goeppinger SR, Kassim O, et al. Safety and efficacy of combination treatment with calcineurin inhibitors and vedolizumab in patients with refractory inflammatory bowel disease. Clin Gastroenterol Hepatol. $2019 \mathrm{Feb}$ 1;17(3):486-93.

92 Mitrev N, Vande Casteele N, Seow CH, Andrews JM, Connor SJ, Moore GT, et al. Review article: consensus statements on therapeutic drug monitoring of anti-tumour necrosis factor therapy in inflammatory bowel diseases. Aliment Pharmacol Ther. 2017;46:1037-53.

93 Papamichael K, Cheifetz AS, Melmed GY, Irving PM, Vande Casteele N, Kozuch PL, et al. Appropriate therapeutic drug monitoring of biologic agents for patients with inflammatory bowel diseases. Clin Gastroenterol Hepatol. 2019;17(9): 1655-e3.

94 Feuerstein JD, Nguyen GC, Kupfer SS, FalckYtter Y, Singh S; American Gastroenterological Association Institute Clinical Guidelines Committee. American Gastroenterological Association Institute Guideline on Therapeutic Drug Monitoring in inflammatory bowel disease. Gastroenterology. 2017 Dec;153(3): $827-34$.

95 Rosario M, French JL, Dirks NL, Sankoh S, Parikh A, Yang H, et al. Exposure-efficacy relationships for vedolizumab induction therapy in patients with ulcerative colitis or Crohn's disease. J Crohns Colitis. 2017;11(8): 921-9.
96 Osterman MT, Rosario M, Lasch K, Barocas M, Wilbur JD, Dirks NL, et al. Vedolizumab exposure levels and clinical outcomes in ulcerative colitis: determining the potential for dose optimisation. Aliment Pharmacol Ther. 2019 Feb;49(4):408-18.

97 Singh S, Dulai PS, Vande Casteele N, Battat R, Fumery M, Boland BS, et al. Systematic review with meta-analysis: association between vedolizumab trough concentration and clinical outcomes in patients with inflammatory bowel diseases. Aliment Pharmacol Ther. 2019;50:848-57.

98 Barre A, Colombel JF, Ungaro R. Review article: predictors of response to vedolizumab and ustekinumab in inflammatory bowel disease. Aliment Pharmacol Ther. 2018; 47(7):896-905.

99 Dreesen E, Verstockt B, Bian S, de Bruyn M, Compernolle G, Tops S, et al. Evidence to support monitoring of vedolizumab trough concentrations in patients with inflammatory bowel diseases. Clin Gastroenterol Hepatol. 2018;16(12):1937-e8.

100 Ribaldone DG, Pellicano R, Vernero M, Caviglia GP, Saracco GM, Morino M, et al. Dual biological therapy with anti-TNF, vedolizumab or ustekinumab in inflammatory bowel disease: a systematic review with pool analysis. Scand J Gastroenterol. 2019 Apr 3; 54(4):407-13.

101 Yang E, Panaccione N, Whitmire N, Dulai PS, Vande Casteele N, Singh S, et al. Efficacy and safety of simultaneous treatment with two biologic medications in refractory Crohn's disease. Aliment Pharmacol Ther. 2020;51(11):1031-8.

102 Motoya S, Watanabe K, Ogata H, Kanai T, Matsui T, Suzuki Y, et al. Vedolizumab in Japanese patients with ulcerative colitis: a phase 3, randomized, double-blind, placebo-controlled study. PLoS One. 2019 Feb 26; 14(2): $\mathrm{e} 0212989$

103 Watanabe K, Motoya S, Ogata H, Kanai T, Matsui T, Suzuki Y, et al. Effects of vedolizumab in Japanese patients with Crohn's disease: a prospective, multicenter, randomized, placebo-controlled Phase 3 trial with exploratory analyses. J Gastroenterol. 2020 Mar;55(3):291-306.

104 Ooi CJ, Hilmi IN, Kim HJ, Jalihal U, Wu DC, Demuth D, et al. Efficacy and safety of vedolizumab in ulcerative colitis in patients from Asian countries in the GEMINI 1 study. Intest Res. 2020 Sep 4.

105 Okamoto H, Dirks NL, Rosario M, Hori T, Hibi T. Population pharmacokinetics of vedolizumab in Asian and non-Asian patients with ulcerative colitis and Crohn's disease. Intest Res. 2020 Jul 10.

106 Matsuoka K, Kobayashi T, Ueno F, Matsui $\mathrm{T}$, Hirai $\mathrm{F}$, Inoue $\mathrm{N}$, et al. Evidence-based clinical practice guidelines for inflammatory bowel disease. J Gastroenterol. 2018 Mar 1; 53(3):305-53.
107 Ling KL, Hilmi I, Raja Ali RA, Leong RW, Leung WK, Ng SC, et al. Asian Pacific Association of Gastroenterology (APAGE) Inflammatory Bowel Disease (IBD) Working Party guidelines on IBD management during the COVIDQ19 pandemic. JGH Open. 2020 Jun;4(3):320-3.

108 Soendergaard C, Seidelin JB, Steenholdt C, Nielsen OH. Putative biomarkers of vedolizumab resistance and underlying inflammatory pathways involved in IBD. BMJ Open Gastroenterol. 2018 May 1;5(1):e000208.

109 Boden EK, Shows DM, Chiorean MV, Lord JD. Identification of candidate biomarkers associated with response to vedolizumab in inflammatory bowel disease. Dig Dis Sci. 2018 Sep 1;63(9):2419-29.

110 Verstockt B, Verstockt S, Veny M, Dehairs J, Arnauts K, Van Assche G, et al. Expression levels of 4 genes in colon tissue might be used to predict which patients will enter endoscopic remission after vedolizumab therapy for inflammatory bowel diseases. Clin Gastroenterol Hepatol. 2020 May 1;18(5): 1142-51.e10.

111 Paul S, Williet N, Di Bernado T, Berger AE, Boschetti G, Filippi J, et al. Soluble mucosal addressin cell adhesion molecule 1 and retinoic acid are potential tools for therapeutic drug monitoring in patients with inflammatory bowel disease treated with vedolizumab: a proof of concept study. J Crohns Colitis. 2018;12(9):1089-96.

112 Battat R, Dulai PS, Vande Casteele N, Evans E, Hester KD, Webster E, et al. Biomarkers are associated with clinical and endoscopic outcomes with vedolizumab treatment in ulcerative colitis. Inflamm Bowel Dis. 2019; 25(2):410-20.

113 van der Valk ME, Mangen MJ, Leenders M, Dijkstra G, van Bodegraven AA, Fidder HH, et al. Healthcare costs of inflammatory bowel disease have shifted from hospitalisation and surgery towards anti-TNFa therapy: results from the COIN study. Gut. 2014;63: 72-9.

114 Sánchez-Moya AI, Dauden E. Incidence of tuberculosis infection in psoriatic patients on anti-TNF therapy: report of a case series with 144 patients. J Eur Acad Dermatol Venereol. 2011;25(6):730-3.

115 Young K, Ho AD, Ho Andrew D. Screening and treatment of tuberculosis in patients with inflammatory bowel disease in a community-based, safety net hospital. Am J Gastroenterol. 2017 Oct;112:S381-2.

116 Loomba R, Liang TJ. Hepatitis B reactivation associated with immune suppressive and biological modifier therapies: current concepts, management strategies, and future directions. Gastroenterology. 2017 May 1; 152(6):1297-309. 